\title{
Producing the consumer price index (CPI) and the COVID-19 pandemic in Latin America and the Caribbean
}

\section{Summary}

In the context of the global coronavirus disease (COVID-19) pandemic, the Economic Commission for Latin America and the Caribbean (ECLAC) is preparing a series of short publications with relevant policy recommendations for this period. This note makes several recommendations for the continued collection of price information from which the consumer price index (CPI) is calculated.

\section{Introduction}

In order to contain the spread of COVID-19, many Latin American and Caribbean governments have decided to restrict the movement of people through quarantine measures. This has interrupted statistical operations in which information is collected face to face in the field. Thus, the institutions responsible for producing official statistics must address complex challenges in order to continue providing their authorities and users with timely and high-quality statistics, including the CPI.

In view of this situation, the Statistics Division of ECLAC sent out a short questionnaire to the national statistical offices (NSOs) and central banks of Latin America and the Caribbean, to learn about the effects that the health emergency was having on the functioning of statistical institutions. Responses from 20 countries indicated that, as at 20 March, they had all declared some form of health emergency as a result of COVID-19.

A series of videoconferences have been held since 24 March to assess the impacts of the COVID-19 pandemic on statistical operations. ${ }^{1}$ These videoconferences have been convened by ECLAC, in conjunction with the International Labour Organization (ILO) and the National Institute of Statistics (INE) of Chile, in its capacity as coordinator of the virtual talks of the Knowledge Transmission Network (KTN) of the Statistical Conference of the Americas, chaired by the National Administrative Department of Statistics (DANE) of Colombia.

In order to learn about the progress made, teleconferences and regular consultations were also held with the countries of the region during the first half of March and again at the end of the month.

This document seeks to provide information about the state of affairs in the region, and to disseminate some of the recommendations agreed with the countries to address the COVID-19 pandemic in relation to the compilation of data for the CPI. Although the analysis applies to this particular indicator, the considerations can be extended to the compilation of price system information in general, where appropriate. The agreed recommendations are based on international manuals and guidelines that the countries had already developed in response to natural disasters or social upheaval throughout their history.

See [online] https://rtc-cea.cepal.org/en/conectados-rtc/planes-de-contigencia-adoptados-por-lasoficinasnacionales-de-estadistica-ante-la.

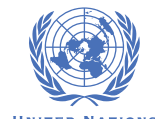

COVID-19 RESPONSE

\section{Summary}

Introduction

A. CPI price survey and data processing in March 2020

B. Imputation methods according to international CPI methodological criteria and calculation process

C. Challenges observed in the implementation of alternative collection modalities

D. Dissemination offigures in the new scenario

E. Recommendations

F. The representativeness of the CPI

Annex 1 


\section{A. CPI price survey and data processing in March 2020}

By mid-March, the governments of all the countries of the region had adopted measures to restrict people's movement by declaring a health emergency and imposing quarantine. As a result, the statistical institutions in the countries had to implement alternative modalities for collecting information and, in the case of the CPI, goods and services price data.

The following situations were identified from the country survey results:

- Between $60 \%$ and $80 \%$ of prices were collected for March 2020.

- Unobserved prices that correspond to seasonal goods or temporary situations (for example, seasonable vegetables that are not available in March or educational services that have a limited pricing frequency) and that were observed in other periods contribute to the percentage of uncollected price data.

- Most statistical institutions were able to collect price data in the first two weeks following the usual modality, that is, face-to-face collection in the field, and some were even able to do so in the third week of March, before the quarantine measures came into force.

- Establishments that provide recreational and cultural services, as well as restaurants and hotels were closed before the end of the month in most of the countries of the region, so the price surveys for those sectors could not be completed. Those sectors account for less than $10 \%$ of the total prices to be collected.

- March 2020 will have a higher percentage of imputation than usual (by between 3\% and $5 \%$ ) because collection was affected by the introduction of quarantine measures in the countries, which, in some cases, led to the closure of premises, restrictions on the movements of price collectors, and greater demand for certain basic goods, causing a temporary drop in stocks, among other difficulties. For these reasons, it is expected the between $10 \%$ and $30 \%$ of the prices will have to be imputed.

Table 1

Main aspects of CPI price data collection as of March 2020

\begin{tabular}{|l|l|l|}
\hline $\begin{array}{l}\text { Percentage of } \\
\text { prices collected }\end{array}$ & Effects of the health emergency & $\begin{array}{l}\text { Categories affected by } \\
\text { the health emergency }\end{array}$ \\
\hline Between $60 \%$ and $80 \%$ & $\begin{array}{l}\text { Restrictions on the movements } \\
\text { of price collectors }\end{array}$ & $\begin{array}{l}\text { All those sectors where prices } \\
\text { are collected face-to-face }\end{array}$ \\
\hline $\begin{array}{l}\text { Establishments closed } \\
\text { Recreation services: cinemas, } \\
\text { theatres, sporting events, } \\
\text { among others }\end{array}$ \\
\hline Products temporarily unavailable & $\begin{array}{l}\text { Food away from home services, } \\
\text { hotel services }\end{array}$ \\
\hline & $\begin{array}{l}\text { Personal care and household } \\
\text { cleaning products }\end{array}$ \\
\hline
\end{tabular}

Source: Economic Commission for Latin America and the Caribbean (ECLAC), on the basis of official information from the countries.

The new conditions pose a challenge to the production of official statistics in each country, especially for those statistical operations that involve ongoing and face-to-face research in the territories. Therefore, new price collection modalities had to be implemented, using alternative procedures, where possible, based on information and communications technologies (ICTs). The statistical institutions decided to carry out their collection operations by telephone or email, or via the Internet (some data sources have websites or social media accounts, which facilitates direct research) or e-commerce websites, as well as updated catalogues (printed or digital), and price and product information provided by institution officials as a result of personal purchases. 
In some countries, these new modalities have led to improvements in the coverage of the price survey, extending it to a greater number of goods and services, which account for between $10 \%$ and $30 \%$ of the prices to be collected. Lastly, thanks to these new tools, the statistical institutes collected sufficient data to calculate the CPI for March (observations that covered over $50 \%$ of total data to be collected). The information that was not collected should have been imputed according to the methods defined in the respective calculation algorithms of each institution as set out in their methodologies.

\section{B. Imputation methods according to international CPI methodological criteria and calculation process}

In the event of missing (unobserved) prices, values should be imputed according to the methodological criteria of the country, which should be in line with international recommendations. ${ }^{2}$ Countries have an imputation methodology for missing price observations, depending on whether the product is seasonal or not, with an average imputation rate per month of between 3\% and 7\%. However, in the current scenario, the ratio of missing price observations will be higher than usual and, therefore, the percentage of prices to be imputed will be higher.

Imputation procedures seek to assign a price variation to a missing price observation. To this end, international recommendations suggest different imputation methods depending on the type of product and the level of disaggregation required. The imputation rules are applied in ascending order from the elementary aggregate (variety-outlet) to the higher levels of aggregation (product). The traditional imputation mechanisms are described below.

(a) Price observation missing for a specific variety from a specific outlet: the geometric mean for the same specific variety from other outlets is imputed.

(b) Price observations missing for a specific variety from all reporting outlets: the geometric mean for all varieties of the same product for which price information is available is imputed for that variety and for all outlets

(c) Price observations missing for all varieties of the product from all outlets: the geometric mean for all products on the next aggregation level up is imputed.

(d) For the higher levels of aggregation: the mechanism outlined in paragraph (c) applies.

(e) Price observations missing for seasonal products: these are collected only in the periods in which they are available; prices are kept constant for the rest of the year.

(f) In the event that an observation cannot be imputed by the prices of the nearest aggregate in the same level or higher aggregation levels, the previous price is maintained, that is, the price observed in the previous period.

A flow chart prepared by Eurostat illustrates the procedure to follow to calculate the CPI (see diagram 1).

In addition, when applying the respective calculation algorithms for the imputations for March 2020, some countries have analysed the results for the same period in February and March 2018 and 2019, in order to identify behaviour patterns and thus validate the values for March 2020, particularly for non-seasonal products.

2 See the international recommendations in International Labour Organization (ILO) and others, Consumer Price Index Manual: Concepts and Methods, 2020 [online] https://www.imf.org/en/Data/Statistics/cpi-manual, document endorsed at the fifty-first session of the United Nations Statistical Commission, and in European Union, Harmonised Index of Consumer Prices (HICP) Methodological Manual, Luxembourg, 2018 [online] https://ec.europa.eu/eurostat/documents/3859598/9479325/KS-GQ-17-015-EN-N.pdf/d5e63427-c588479f-9b19-f4b4d698f2a2. 


\section{Diagram 1}

Eurostat decision tree

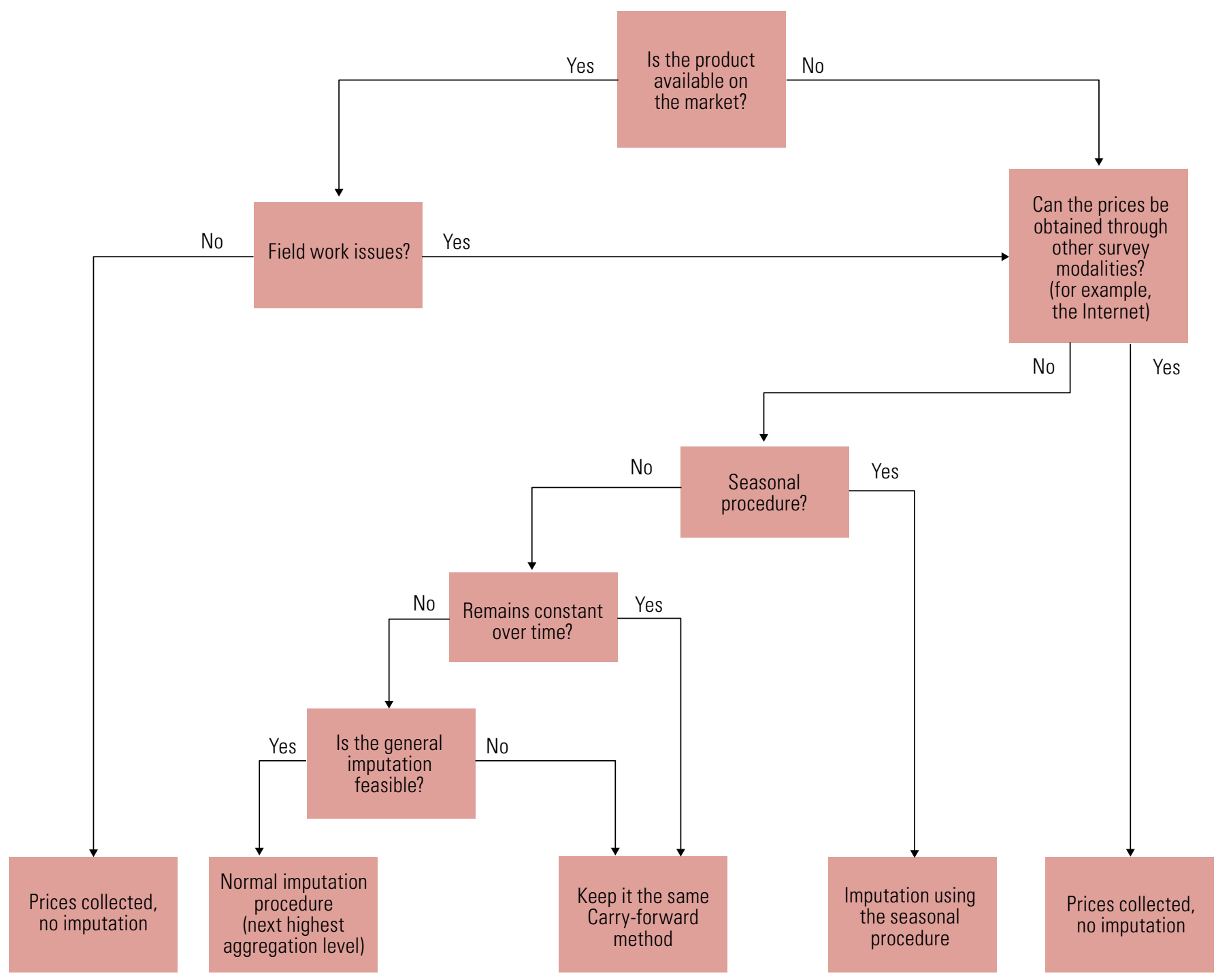

Source: Eurostat, presentation given at the extraordinary meeting of the Intersecretariat Working Group on Price Statistics, 25 March 2020, unpublished.

\section{Challenges observed in the implementation of alternative collection modalities}

Some difficulties were encountered when implementing alternative price collection modalities. These include training price collectors on how to use the survey modalities and establishing a mechanism to contact regular informants to let them know of the change in survey modality and to ask for their support and availability in this new scenario. Another difficulty arises from the fact that outlets closed before they could be contacted. All these situations should be improved, where possible, in order to carry out price surveys in the coming months. 


\section{Dissemination of figures in the new scenario}

Since the new scenario affects price collection and coverage, users must be informed of the exact level of coverage achieved and the measures taken to ensure ongoing price surveys. It is therefore recommended that a footnote be added to the published figures or a simple but clear note on coverage be included in the regular publication. It is also recommended that a technical note be prepared detailing the measures taken with regard to how the survey was conducted and the procedures to impute the missing observations, as well as indicating the effects of those measures. For example, the National Institute of Statistics and Censuses (INEC) of Ecuador prepared a technical note ${ }^{3}$ on this issue for its March 2020 publication. Below is an extract from the methodological note prepared by the National Institute of Statistics (INE) of Chile for its October indicator.

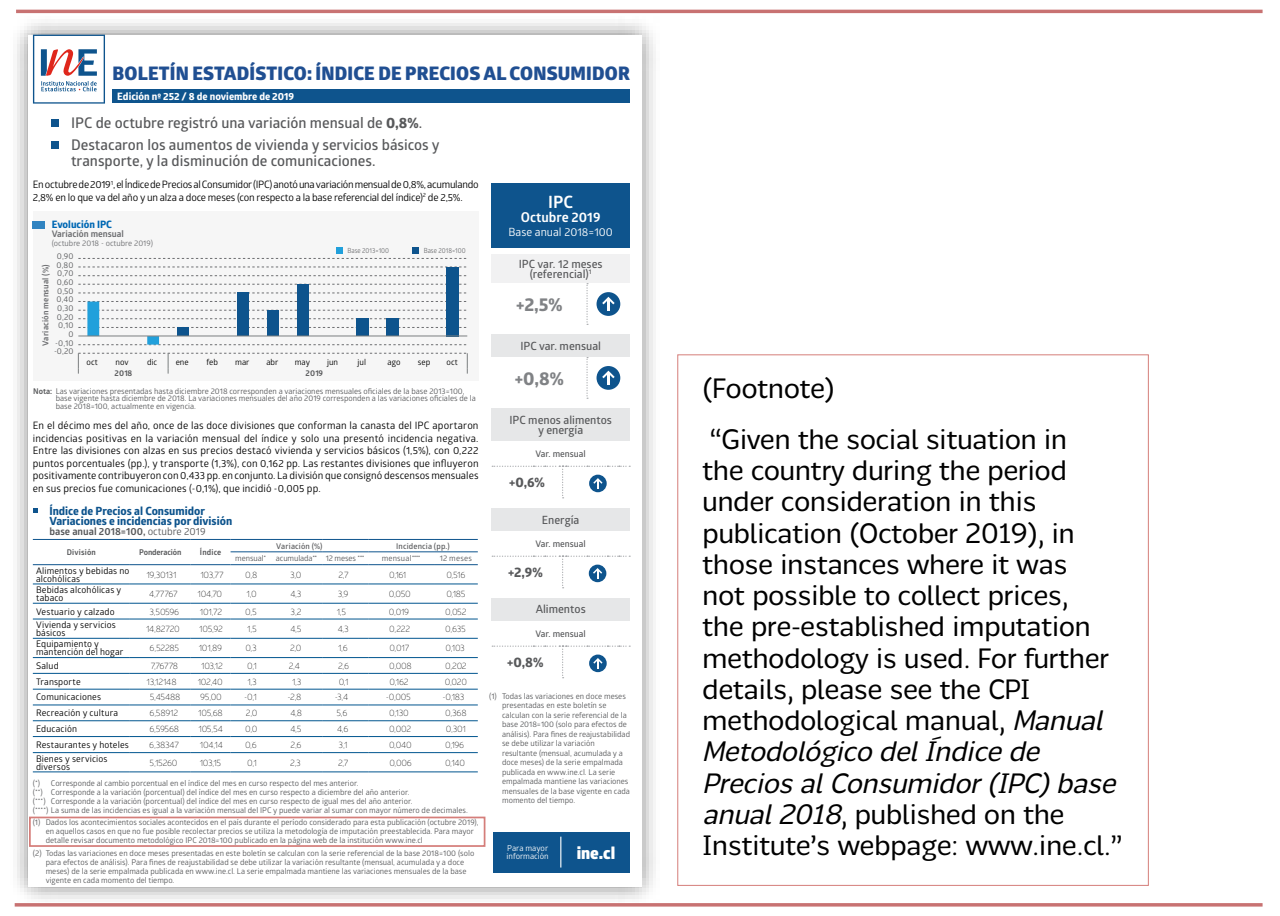

Source: National Institute of Statistics (INE) of Chile.

\section{E. Recommendations}

In the light of this health emergency and the difficulties identified, the main objectives are to maintain adequate coverage and ensure the quality of the information collected, as well as the quality of the statistical end products, in this case the CPI.

The statistical institutions that produce the CPI should therefore continue to work on adapting their data (price) collection processes, and proceeding with the collection, processing and timely dissemination of their results.

To meet this challenge, these institutions must build the necessary capacities in their teams quickly, in order to implement remote collection modalities using digital technologies instead of traditional methods based on face-to-face interviews between the price collector and the informant. In order to ensure the continuity of the survey processes, one of the key factors in selecting new modalities is the time it will take to implement them, given, for example, the need to train staff in using new methodologies, technologies and skills to obtain the widest and best coverage possible.

See [online] https://www.ecuadorencifras.gob.ec/documentos/web-inec/Inflacion/2020/Marzo-2020/Nota_tecnica_ cobertura_e_imputacion_03-2020-IPC.pdf. 
It is also important to make the necessary adjustments so that the information obtained can be incorporated into the current systems. Capturing prices from current sources using different survey modalities, either by telephone, email or a limited outlet visit, would allow the prices observed by the CPI informants to be obtained. However, the information collected through digital mechanisms, such as from the informants' websites or through the Internet, as well as the availability of price information, could result in supplementary information being obtained from current sources. This additional information will therefore have to be incorporated into the price databases in a differentiated manner, so that it can be excluded, if it is so decided, once the current health emergency has passed and institutions return to face-to-face collection.

The idea behind this note is to encourage, in light of the current situation, institutions to introduce some flexibility into the price collection process and their imputation methods. Ideally, these options should be exhausted, instead of expanding the sample to include new sources. If outlets are closed, they should not be replaced.

Meanwhile, given that the current contingency could last some time, efforts should be made to improve collection modalities not only in the month of observation but also with a view to the medium and long term, by incorporating new capture mechanisms and carrying out the relevant analyses. The results from the same period in previous years should also be borne in mind in order to be able to know whether the results of the imputations made on the missing prices are consistent with them.

Lastly, it is suggested that institutions that are facing this new price collection reality should:

- Implement new mechanisms to identify, contact and authenticate informants and communicate with them.

- Implement mechanisms to support and monitor workflows when conducting enquiries over the telephone, email or social media with reporting sources.

- Procure or develop ICT systems to support telephone, email and social media enquiries, whether computer assisted or through online data capture portals, if possible, so that they are available as soon as possible to be used by the CPI analysts.

- Implement mechanisms to support analysts in the online capture of information, its verification and validation for incorporation into price databases.

- Ensure secure remote access to computer systems and secure data exchange for analysts and those responsible for CPI data processing and calculations.

- Create new variables to automatically geocode responses to queries and monitor the process.

- Draw on the knowledge acquired in this situation to reflect on the introduction of new mechanisms for the collection of information through technological platforms in the short term.

\section{F. The representativeness of the CPI}

Taking all these challenges into account, compliance objectives must be set to ensure that CPI calculations are of sufficient quality for it to be considered an adequate statistical instrument for monitoring inflation and household consumer prices. Given that a certain percentage of prices are usually missing, owing to non-observation, it is suggested that, in the current situation, at least $50 \%$ of the information should be observed in the month in order to calculate and publish the CPI. 


\section{Annex 1}

Examples of imputation procedures

A. Variety imputation

\begin{tabular}{|c|c|c|c|c|c|c|c|c|c|c|c|}
\hline Item code & Level & $\begin{array}{l}\text { Outlet } \\
\text { code }\end{array}$ & Description & Specification & $\begin{array}{c}\text { Price } \\
(\mathrm{t}-1)\end{array}$ & $\begin{array}{c}\text { Price } \\
(\mathrm{t})\end{array}$ & $\begin{array}{l}\text { Relative } \\
(\mathrm{t} / \mathrm{t}-1)\end{array}$ & $\begin{array}{c}\text { Geometric } \\
\text { mean }\end{array}$ & $\begin{array}{l}\text { Variety-Outlet } \\
\text { index }\end{array}$ & $\begin{array}{l}\text { Variety } \\
\text { index }\end{array}$ & \\
\hline 02.1 .3 & Class & & Beer & & & & & & & & Variation \\
\hline 02.1 .3 .0 & Subclass & & Beer & & & & & & & & of observed \\
\hline 02.1.3.0.1 & Product & & National beer & & & & & & & & is applied to \\
\hline 02.1.3.0.1.1 & Variety & & National lager & & & & & & & 101.09 & $\begin{array}{l}\text { the missing } \\
\text { prices }\end{array}$ \\
\hline 02.1 .3 .0 .1 .1 & Variety-Outlet & $101-1$ & Supermarket 1 & Bavaria, bottle & 1090 & 1100 & 100.92 & & 100.92 & & \\
\hline $02 \cdot 1.3 .0 .1 .1$ & Variety-Outlet & $101-2$ & Supermarket 2 & Pilsen 6.0, bottle & 770 & 775 & 100.65 & $\downarrow$ & 100.65 & & \\
\hline 02.1 .3 .0 .1 .1 & Variety-Outlet & $101-3$ & Supermarket 3 & Imperial, $710 \mathrm{ml}$ can & 1180 & 1200 & 101.69 & 101.09 & 101.69 & & \\
\hline 02.1.3.0.1.1 & Variety-Outlet & $103-1$ & Off-licence 1 & Pilsen 6.0, bottle & 818 & 827 & 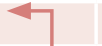 & & 101.09 & & \\
\hline 02.1 .3 .0 .1 .1 & Variety-Outlet & $103-2$ & Off-licence 2 & Imperial, bottle & 1190 & 1203 & & & 101.09 & & \\
\hline $02.1 .3 \cdot 0.1 .1$ & Variety-Outlet & $103-3$ & Off-licence 3 & Bavaria, bottle & 1030 & 1041 & & & 101.09 & & \\
\hline $02.1 \cdot 3 \cdot 0.1 .2$ & Variety & & National dark beer & & & & & & & & \\
\hline $02 \cdot 1 \cdot 3 \cdot 0.2$ & Product & & Imported beer & & & & & & & & Imputed price, \\
\hline 02.1 .3 .0 .2 .1 & Variety & & Imported lager & & & & & & & & observed pric \\
\hline $02 \cdot 1 \cdot 3 \cdot 0.2 .2$ & Variety & & Imported dark beer & & & & & & & & variation \\
\hline
\end{tabular}

This spreadsheet illustrates the imputation procedure to be followed when prices are missing for some varieties, as in the case of the prices for "National beer" from outlets classified as "off-licences".

B. Product imputation

\begin{tabular}{|c|c|c|c|c|c|c|c|c|c|c|}
\hline Item code & Level & $\begin{array}{l}\text { Outlet } \\
\text { code }\end{array}$ & Description & Specification & $\begin{array}{c}\text { Price } \\
(\mathrm{t}-1)\end{array}$ & $\begin{array}{l}\text { Price } \\
(\mathrm{t})\end{array}$ & $\begin{array}{l}\text { Relative } \\
(\mathrm{t} / \mathrm{t}-1)\end{array}$ & $\begin{array}{l}\text { Geometric } \\
\text { mean }\end{array}$ & Product index & \\
\hline 09.3 .2 .2 & Subclass & & $\begin{array}{l}\text { Products for pets and } \\
\text { other domestic animals }\end{array}$ & & & & & & & $\begin{array}{l}\text { Imputed } \\
\text { price, using }\end{array}$ \\
\hline 09.3 .2 .2 .1 & Product & & Veterinarian services & & & & & & 100.85 & ved \\
\hline \multirow[t]{3}{*}{ 09.3.2.2.1.1 } & Variety & & Vaccination services & & & 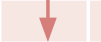 & & 100.85 & & \\
\hline & Variety-Outlet & $201-1$ & Rabies vaccine & Dog under 1 year & 9900 & 9984 & 100.85 & & & \\
\hline & Variety-Outlet & $201-2$ & Rabies vaccine & Dog under 1 year & 10800 & 10891 & 100.85 & & & \\
\hline \multirow[t]{3}{*}{09.3 .2 .2 .1 .2} & Variety & & Deworming services & & & & & 100.85 & & \\
\hline & Variety-Outlet & $201-1$ & $\begin{array}{l}\text { Consultation with } \\
\text { deworming }\end{array}$ & 3-month-old dog & 5500 & 5547 & 100.85 & & & \\
\hline & Variety-Outlet & $201-3$ & $\begin{array}{l}\text { Consultation with } \\
\text { deworming }\end{array}$ & 3-month-old dog & 6500 & 6555 & 100.85 & & & Index calculated \\
\hline 09.3 .2 .2 .2 & Product & & Pet food & & & & & & 100.85 & \\
\hline \multirow[t]{4}{*}{ 09.3.2.2.2.1 } & Variety & & Dog food & & & & & 101.12 & & \\
\hline & Variety-Outlet & $101-1$ & Dry food for adult dogs & Pro Pet, $1500 \mathrm{~g}$ & 4250 & 4300 & 101.18 & & & \\
\hline & Variety-Outlet & $101-2$ & Dry food for adult dogs & Super Perro, $2000 \mathrm{~g}$ & 6900 & 7000 & 101.45 & & & \\
\hline & Variety-Outlet & $104-1$ & Dry food for adult dogs & Beneful, $1590 \mathrm{~g}$ & 10950 & 11030 & 100.73 & & & \\
\hline \multirow[t]{4}{*}{09.3 .2 .2 .2 .2} & Variety & & Cat food & & & & & 100.58 & & \\
\hline & Variety-Outlet & $101-1$ & Dry cat food & Cat Chow, $1500 \mathrm{~g}$ & 5400 & 5430 & 100.56 & & & \\
\hline & Variety-Outlet & $101-2$ & Dry cat food & Whiskas, $1500 \mathrm{~g}$ & 3880 & 3890 & 100.26 & & & \\
\hline & Variety-Outlet & $104-2$ & Dry cat food & Royal Canin, $2000 \mathrm{~g}$ & 16370 & 16520 & 100.92 & & & \\
\hline
\end{tabular}

This example shows the lack of prices for a product "Veterinarian services", which is imputed to the variation of another product, namely "Pet food". 
C. Subclass imputation

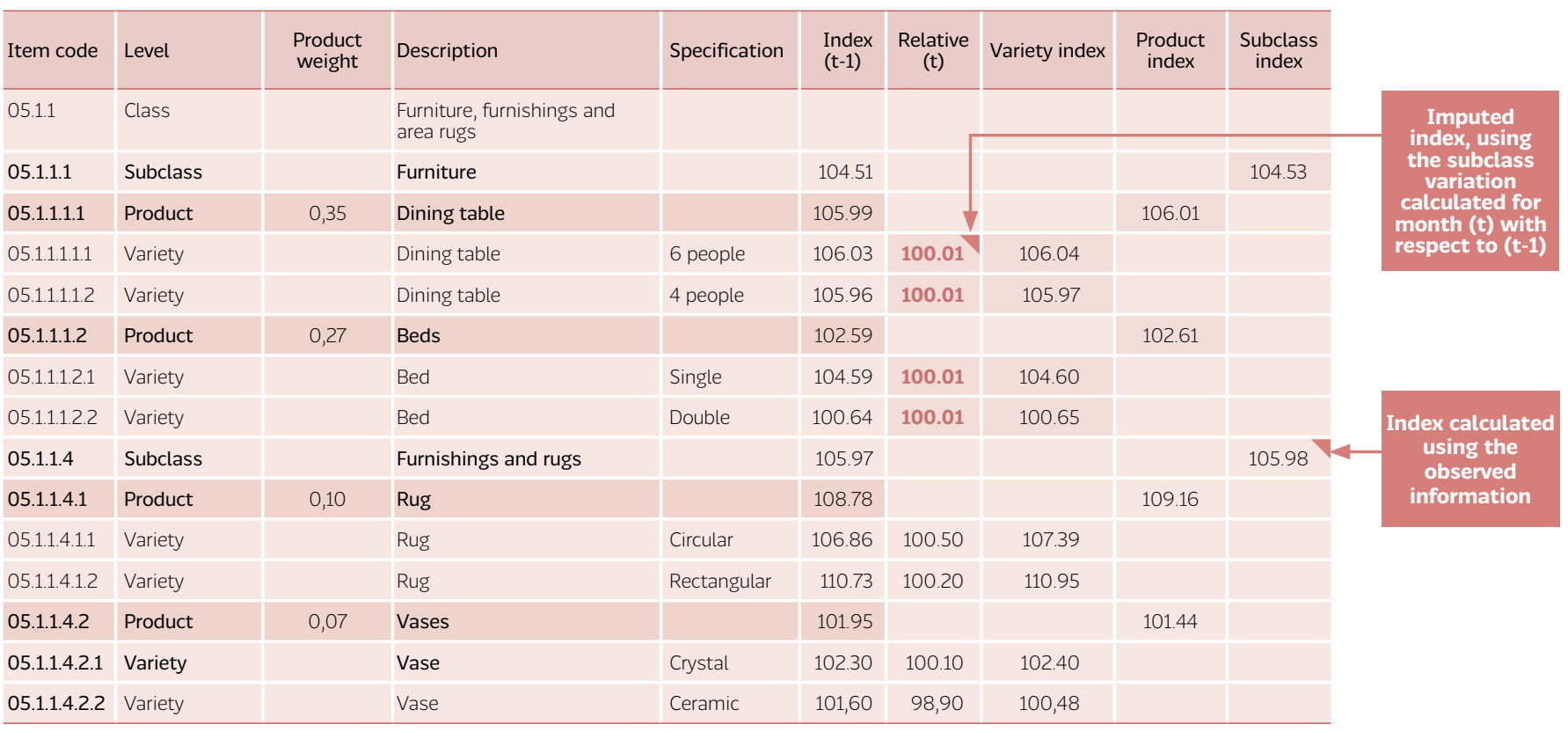

This spreadsheet shows the subclass imputation using information from the other observed subclass.

Source: Economic Commission for Latin America and the Caribbean (ECLAC).

This document is part of a series of reports prepared by the Economic Commission for Latin America and the Caribbean (ECLAC) on the evolution and effects of the COVID-19 pandemic in Latin America and the Caribbean. It was prepared by the Statistics Division, directed by Rolando Ocampo, under the general coordination of Alicia Bárcena, Executive Secretary of ECLAC.

Copyright (C) United Nations, 2020 